\title{
Microwave installation for accelerating the process of salting the food products
}

\author{
Dmitrii Poruchikov ${ }^{1, *}$, Irina Ershova $^{1}$, Alexey Vasiliev ${ }^{1}$, Gennady Samarin ${ }^{1}$, Viacheslav Ruzhyev ${ }^{2}$, Dmitry Normov ${ }^{3}$, \\ Alexander Zhukov ${ }^{4}$ \\ ${ }^{1}$ FSAC VIM, 109428, Moscow, Russian Federation \\ ${ }^{2}$ FSBEI HE SPb SAU, 109428, Saint-Petersburg, Russian Federation \\ ${ }^{3}$ FSBEI HE Kuban SAU, 109428, Krasnodar, Russian Federation \\ ${ }^{4}$ Velikie Luki SAA, 109428, Pskov region, Velikie Luki, Russian Federation
}

\begin{abstract}
This article contains a description of the developed installation for salting and heat treatment of raw meat, which allows accelerate the salting process due to electrophysical effects. To provide the population with quality products from small-sized meat raw materials with reduced energy consumption, it is necessary to create rational conditions for their processing, ensuring the intensification of production processes based on the use of non-traditional types of energy carriers, and in particular electromagnetic waves of ultrahigh frequency. When raw materials are introduced into the resonator chamber in the developed installation, a traveling component appears in the standing wave, which transfers energy from the source to the raw material, which ensures its heating.
\end{abstract}

\section{Introduction}

According to static data for 2017 , the total amount of processed subproducts (liver of cattle and pigs, heart and muscle stomach of birds) in the Russian Federation is 60.57 thousand tons, in the Nizhny Novgorod region 0.38 thousand tons, in the Chuvash Republic - 0.48 thousand tons. With the increase in livestock production, the question of rational use of by-products arises. Currently, such raw materials are mainly sold without processing. Due to its specific features, microwave heating allows to intensify the heat-mass transfer and diffusion processes in the conditions of heat and moisture processing of raw meat. When raw meat is introduced into the standing wave, a running component appears in the latter, which transfers energy from the source to the raw material, which ensures its heating. Intensification of production processes based on the use of non-traditional types of energy carriers, and in particular, electromagnetic waves of the microwave frequency and the electrohydraulic effect [1]. Microwave energy plays a significant role in food processing $[2,3]$.

Therefore, we propose a method of thermomechanical impact on such raw materials in the electromagnetic field of ultra-high frequency (EMF UHF) in the process of massaging in brine to obtain boiled products. The process of massaging raw meat for 3-4 hours after injection with brine in the production of smoked products is widespread, but for small-scale raw materials, this technology is excluded due to the difficulty of injecting with brine.

In Russia, as well as abroad, technologies for creating products of microwave electronics are classified as critical technologies. The Strategic Program for Research of the Technological Platform "Microwave Technology" June 17, 2016 was approved. Therefore, the development and justification of the parameters of the microwave installation for heat treatment in the process of massaging small-sized meat raw materials is relevant.

The purpose of research is to develop the principle of heat treatment and the microwave installation for heat treatment of raw meat in the massaging process to improve product quality.

In accordance with the purpose set the following research objectives:

1. Based on an analysis of existing meat massager and constructional designs of microwave resonators installations intended for the processing of raw meat, heat treatment to develop the principle of accelerating massoob-mennye processes in small-sized raw meat in the massaging process, which increases the quality of the finished product.

2. To substantiate the modes of operation of the microwave installation with a resonator-drum, taking into account regression models and the results of studies of physico-chemical, microbiological and organoleptic indicators of the meat product. To produce and test the installation with a resonator-drum under production conditions, accelerating the process of heat treatment of raw materials.

3. To evaluate the technical and economic efficiency of the installation implementation in farms; to develop scientifically based practical recommendations on the implementation of the principle of accelerating the heat

\footnotetext{
*Corresponding author: dv.poruchikov@yandex.ru
} 
treatment of raw materials by massaging in brine, ensuring a reduction in operating costs and an improvement in the quality of the meat product.

The object of research is the processes that ensure the acceleration of heat treatment of small-sized meat raw materials, a prototype of a microwave installation with a resonator-drum, simultaneously performing the function of massaging. Important to monitor the geometric parameters of agricultural equipment [4].

The subject of research is to identify patterns of heating of small-sized meat raw materials in the process of distribution of curing substances in the resonator drum due to the thermomechanical effect.

\section{Research methods}

Theoretical studies were carried out using the basic principles of theoretical mechanics, mass transfer and filtration-diffusion processes, the theory of differential and integral calculus. Three-dimensional modeling of the constructional performance of microwave installations developed with resonators-drums made in the form of a squirrel cage made of pipes, rods or perforated was performed in the Compass-3D V17 program. It is necessary to determine the design and technological parameters of the microwave installation [5].

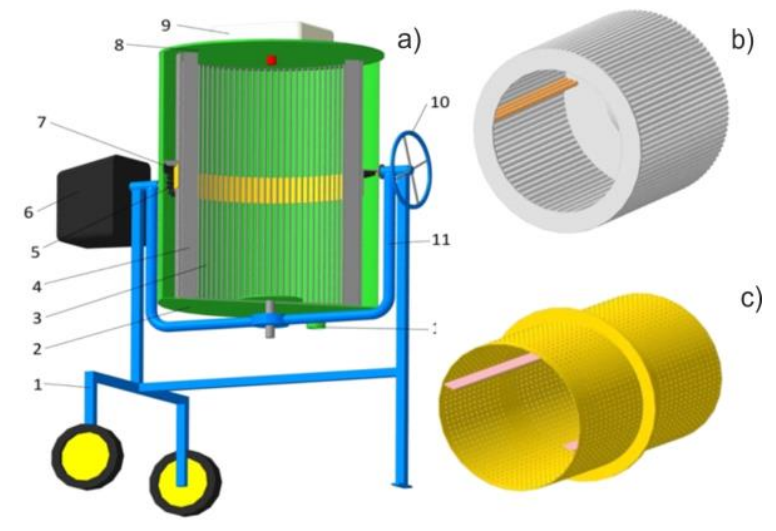

Fig. 1. Microwave installation for heat treatment of raw meat in the process of massaging: a) 3D installation model; b) options for removable cylindrical resonators in the form of a squirrel cage, and 3) perforated; 1 - mobile frame; 2 cylindrical shielding housing; 3 - cylindrical open resonatordrum; 4 - internal edges; 5 - leading gear; 6 - gear motor; 7 ring gear; 8 - case cover; 9 - generator unit; 10 - stopper; 11 pivoting frame for supporting and changing the angle of inclination of the installation; 12 - drain pipe.

\section{Results and discussion}

Constructional designs and the principle of operation of microwave installations with resonator-drums are described.

1. Microwave installation for heat treatment of raw meat in the process of massaging (patent No. 2650540)

In order to intensify filtration-diffusion processes, it is proposed to carry out the process of massaging raw materials in EMF microwave. The installation provides a combination of mechanical and electrophysical effects on raw materials without vacuum in the drum. The microwave installation (figure 1) of cyclic action for heat treatment of raw meat contains a cylindrical screening housing 2 , inside of which an open cylindrical resonator 3 with internal fins 4 is coaxially mounted. It rotates due to the coupling of the pinion gear 5 mounted on the shaft of the gear motor 6 . The ring gear 7 is mounted on the rim around the lateral surface of the resonator-drum.

A generator block 9 is installed on the lid 8 of the shielding case. It is located on the side of the open end of the resonator chamber. Due to the stopper 10 and the swing frame 11, you can change the angle of inclination of the installation. At the bottom of the housing is provided a drain pipe 12 .

The installation works as follows. Set the working chamber in a vertical position. Open the cover 8 of the housing and load raw meat with brine with the drain pipe closed. Close the lid and lock the drum in the working position - horizontally. Turn on the gear motor and microwave generator. The resonator-drum rotates at a speed less than the critical one due to the coupling of the pinion gear on the shaft of the gearmotor with the ring gear. In the chamber, the raw material is exposed to the EPSVC and is endogenously heated. During the rotation of the resonator-drum, the raw material rises to a certain height due to the ribs and falls, i.e. massaging occurs, accelerating the filtration-diffusion process. Raw material rises in a rotating resonator and falls under the action of gravity. The process is repeated many times during the cooking of raw materials, so that the product composition is homogeneous, with low porosity. The particles of the components of the raw materials move along complex trajectories, which leads to active mixing, the creation of vortex flows. The driving force salting process is the difference in salt concentrations in the feed and brine, and temperature gradient. The rate of salt accumulation in raw materials decreases sharply in the process of salting, due to the decrease in the difference in concentrations in the system. Therefore, it is necessary to determine the factor, the effect of which would lead to an increase in the salt concentration in the tissue of the raw material, causing an acceleration of the salting process. Brine is absorbed into the raw meat tissue residues of brine flow down through the slots into the annulus between the resonator and the housing. The effect of mass transfer when massaging meat raw materials is further enhanced due to the effect of EMF microwave. The brine-saturated raw material is boiled. Upon reaching a certain temperature of heating the raw material for a certain period of time, you must turn off the microwave generator and the gearmotor, that is, stop the rotation of the resonator-drum. The remains of the brine drain through the drain pipe. To unload the finished product, remove the installation from the stopper and turn it with a special lever. Open the housing cover, tilt the installation, the open part of the housing and the cavity provide unloading of the finished product. In the installation, the cooking and sterilization of the product can be carried out to extend the shelf life by salting the raw materials and endogenous heating. For the thermomechanical action, different raw materials can be loaded into the resonator-drum; therefore, in each 
particular case, an appropriate removable resonator should be installed. When the liquid fraction prevails in the raw material, it is recommended to install a perforated resonator with small-diameter holes. In the case of thermomechanical processing of small-sized raw materials, use a squirrel cage resonator. The brine volume and salt concentration in it depends on the cavity volume, the type of raw material being processed, the duration and storage temperature of the product. Regulation of technological parameters makes it possible to accurately select the processing mode for each type of feedstock. The installation contains elements of control and management: switch-on toggle switches, indicator lamps, temperature sensors. The advantages of this installation: reduction in overall dimensions; the ability to control and change the operating parameters; ensuring the stability of parameters during operation and exposure to external factors; expansion of production of new types of products, etc.

2. Installation of microwave and infrared power supply to the resonator-drum of pipes with coolant, providing a thermomechanical effect on meat raw materials (patent number 2537548)

The installation (Figure 2) contains in the cylindrical shielding housing 1 a resonant chamber 3 in the form of a squirrel cage assembled from pipes, from the end of which the emitter is directed from the generator unit 5 with the magnetron. The hollow shaft 7 is laid through the central axis of the resonator chamber. The shaft is rigidly connected to the end hollow disk 15 and the annular tube 6 of the resonator chamber. The generator unit and charging port 12 are located on the side of the open end of the resonator. At the bottom of the body there is a drain nipple 14 . The resonator contains blades 4. Grill lamps 2 are installed under the body. Salting brine seeps through the slots 13 between the pipes to the bottom of the body and pours in part of the raw meat in the chamber. In the middle of the hollow shaft 4 has a partition wall 18. The installation works as follows. Raw meat 17 and the curing brine 16 is loaded through the charging port 12, closed. The coolant (steam-water mixture) is supplied to the pipes of the resonator chamber through the coupling 11. The coolant from the pipeline passes through the coupling to the right-hand chamber, since there is a plug in the hollow shaft 7 . Then, bypassing the tubular resonator chamber, enters the left chamber and returns through the pipe into the pipeline network.

The locking nut 10 and the gasket 9 to the bearing assembly 8 limit the flow of coolant. Include a gear motor, which rotates the resonator chamber with a speed less than the critical. At the same time, due to the blades, 4 pieces of meat rise to a certain height and fall, that is, a filtration-diffusion process is underway.

The brine is absorbed into the tissues of raw meat. Turn on the microwave generator. Due to the heat from the pipes and the impact of the EMF microwave, the effect of mass transfer when massaging meat raw materials is further enhanced. Curing substances are mainly redistributed due to exposure to microwave EMF. With further aging in the salting, diffusion transfer is slow, but still faster than in raw meat, which has not been exposed. After massaging the raw meat, the remains of the brine is drained through the drain pipe, turn on the lamp-grill 2 , and the steam-water mixture circulates through the resonator pipes. In this mode, produce boiling and smoking products. Next, turn off the microwave generator, change the coolant in the pipes for coolant (tap water or cooling brine). When this occurs, the cooling of the finished product, after which the rotation of the resonator chamber is stopped. Open the hatch and unload the finished smoked product.

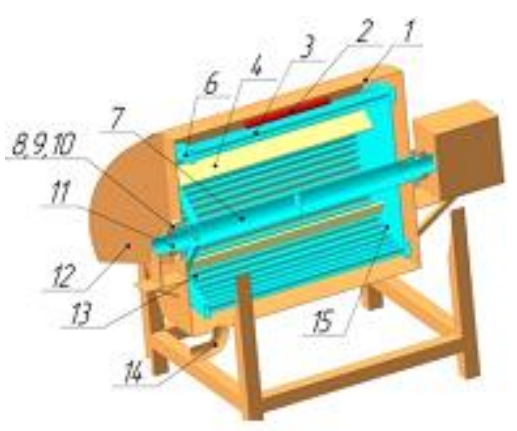

Fig. 2. Installation of microwave and infrared power supply to the resonator - a drum made of pipes with heat carrier, providing a thermomechanical effect on raw meat: 1 - shielding case; 2 - grill lamps; 3 - resonator chamber in the form of squirrel cages; 4 - blades; 5 - generator unit; 6 - ring pipe; 7 hollow shaft; 8 - bearing unit; 9 - dielectric strip; 10 - lock nut; 11 - clutch; 12 - hatch; 13 - the gap between the pipes; 14 drain pipe; 15 - hollow disk; 16 - brine; 17 - lumpy raw meat, 18 - partition.

\section{Conclusions}

1. The principle of combining heat treatment and massaging meat raw materials in one working chamber, proposed on the basis of an analysis of existing meat massagers and structural designs of microwave resonators, realizes the acceleration of sodium chloride distribution in brine and raw materials up to $40 \%$ compared to the massaging process without exposure to EMF microwave

2. Modes of operation of the microwave installation with a resonator-drum, taking into account regression models and the results of studies of physico-chemical, microbiological and organoleptic indicators of the meat product. Manufactured and tested microwave installation with a resonator-drum in production conditions, accelerating the process of heat treatment of small-sized meat raw materials.

3. The economic effect of the use of the installation with a source of microwave energy for heat treatment in the process of massaging small-sized meat raw materials as compared with the complex use of the Gambit-120 meat smoker and the Smokehouse KoptiSam-120NPP makes 400 thousand rubles / year due to reduction of operating costs with the volume of manufactured products , 8 tons per year. Profitability will increase by $13 \%$.

The obtained data allow us to conclude that the diffusion-osmotic processes under the influence of 
microwave waves are intensified to a much greater extent than with conventional mechanical mixing [6].

When processing at the beginning of the process takes place with great ambassador soon Stu, which was later reduced, and there is the alignment of the content of salt.

The main factors that accelerate the penetration of salt into the meat, are the processes of cavitation and microwave pressure, occurring in the microwave field.

Microwave processing affects the moisture retention as a result of heat treatment, so we studied the moisture content in the finished product [7].

In the case of a wet salting with a low concentration brine, the moisture-binding capacity of the meat is increased, with which consistency, juiciness and yield of finished products are primarily associated. As is known, the moisture-binding capacity of meat primarily depends on the number of hydrophilic groups in proteins, which fix water dipoles. It is the higher, the longer the interval between the $\mathrm{pH}$ of the medium and the isoelectric point of the proteins of the meat.

Salt penetrates meat not only through a system of pores and capillaries penetrating tissues, but also osmotically through membranes and shells covering fibers and bundles of them. This leads to an increase in osmotic pressure inside the muscle fiber, which increases the flow of water into it, the amount of osmotically bound moisture and contributes to the swelling of meat.

With prolonged salting, collagen fibers swell well as a result of the introduction of salt molecules of water molecules between peptide chains of protein molecules following the ions and their structure changes to a considerable degree; swelling reaches a maximum at about the 20th knock, and when exposed to microwave, already on the second day after salting.

The water content and moisture binding capacity of the connective tissue is less than muscular.

Thus, under the influence of the microwave, there is a change in the organoleptic and physicochemical parameters, the meat acquires a tender and juicy structure; changing the ratio of protein fractions. The yield of finished products is increased by 2 times due to loosening of the fibers of connective tissue.

\section{References}

[1] A. Belov, A. Modeling the assessment of factors influencing the process of electro-hydraulic water treatment, VESTNIK NGIEI, 11, 103-112 (2018).

[2] I.V. Sirovatka, Improvement of technological processes of manufacturing combic food in economy, Journal of VNIIMZH, 1, 4-11 (2014).

[3] A.N. Vasiliev, D.A. Budnikov, A.A. Vasiliev, Grain simulation process in the heating module universal electrical microwave field at various algorithms of electrical, In Journal of Agricultural Science Don., 1, 33, 12-17 (2016).

[4] A.S.Dorohov, U.V. Kataev, K.A. Ksacnashih, D.M. Skorohodov, Quality control of spare parts of agricultural machinery with automated measuring device, Nauka bez granic, Moscow: Avtograf, 2, 44-50 (2018).

[5] A.V. Rodionova, M.S. Borovkov, M.A. Ershov, Justification of the selected frequency of electromagnetic radiation in physical prophylaxis of harbols, NIVA POVOLZA, 1, 108-110 (2012).

[6] I.G. Ershova, M.V. Belova, D.V. Poruchikov, M.A. Ershov, Heat treatment of fat-containing raw materials with energy of electromagnetic radiation, International research journal, 09, 51, 38-40 (2016).

[7] M.V. Belova, G.V. Nonikova, I.G. Ershova, M.A. Ershov, O.V. Mikhailova, Innovations in technologies of agricultural raw materials processing, Journal of Engineering and Applied Sciences, 11, 6, 1269-1277 (2016).

[8] D. Fiorini, D. Pacetti, R. Gabbianelli, S. Gabrielli, R. Ballini, A salting out system for improving the efficiency of the headspace solid-phase microextraction of short and medium chain free fatty acids, Journal of Chromatography, A on science Dirrect, 1409, 282-287 (28 August 2015).

[9] S.R.A. Rahim, I. Musirin, M.M. Othman, M.H. Hussain, M.H. Sulaiman, A. Azmi, Effect of Population Size for DG Installation using EMEFA, Proceedings of the 2013 ieee 7th international power engineering and optimization conference, PEOCO2013, 746-751 (3-4 June 2013).

[10] N. Izli, O. Taskin, G. Izli, Drying of lime slices by microwave and combined microwaveconvective methods, Italian Journal of Food Science, s. 1, 31, 3 (March 2019). ISSN: 11201770 .

[11] A. Patnaik, R.K. Mishra, ANN Techniques in Microwave Engineering, IEEE Microwave Magazine, book 1, 1, 55-60.

[12] Z. Peng, X. Lin, Z. Li, J.-Y. Hwang, B.-G. Kim, Y. Zhang, G. Li, T. Jiang, Dielectric characterization of Indonesian low-rank coal for microwave processing, 156, 171-177 (February 2017).

[13] P. Kaewwichit, J. Junsomboon, P. Chakartnarodom, C. Tippayasam, T. Srichumpong, P. Thavorniti, C. Leonelli, D. Chaysuwan, Development of microwave-assisted sintering of Portland cement raw meal, Journal of cleaner production, book 142, 3, 1252-1258 (20 January 2017).

[14] Ricardo L. Monteiro, Jade V. Link, G. Tribuzi, Bruno A. M. Carciofi, Joao B. Laurindo, Microwave vacuum drying and multi-flash drying of pumpkin slices, Journal of food engineering, book 232, 1-10 (September 2018).

[14] A. Aguilar-Reynosa, C. Noé Aguilar, A. Romani, R.M. Rodriguez-Jasso, C.N. Aguilar, G. Garrote, H.A. Ruiz, Comparison of microwave and conduction-convection heating autohydrolysis pretreatment for bioethanol production, Bioresource technology, book 243, 273-283 (November 2017). 